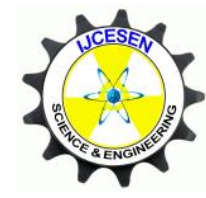

Copyright (C) IJCESEN
International Journal of Computationaland

Experimental $\boldsymbol{S}$ cienceand $\boldsymbol{E N g i n e e r i n g}$

(IJCESEN)

Vol. 5-No.3 (2019)pp. 119-123

http://dergipark.gov.tr/ijcesen

ResearchArticle

\title{
Determination of the Radiation Dose Level in Different Slice Computerized Tomography
}

\section{Osman GÜNAY ${ }^{1,2 *}$, Özcan GÜNDOĞDU ${ }^{2}$, Mustafa Demir $^{3}$, Mohammad ABUQBEITAH $^{3}$, Doğan YAŞAR ${ }^{4}$, Serpil AKÖZCAN ${ }^{5}$, Enis KAPDAN ${ }^{6}$, Onur YARAR ${ }^{1}$}

\author{
${ }^{1}$ Istanbul Okan University, Vocational School of Health Services, Istanbul,Turkey \\ ${ }^{2}$ Kocaeli University, Faculty of Technology, Kocaeli, Turkey \\ ${ }^{3}$ Istanbul University-Cerrahpasa, Cerrahpasa Faculty of Medicine, Departman of Nuclear Medicine, Istanbul, Turkey \\ ${ }^{4}$ Ahi Evran University, Faculty of Art and Science, Kirsehir, Turkey \\ ${ }^{5}$ Kırklareli University, Faculty of Art and Science, Kirklareli, Turkey \\ ${ }^{6}$ TAEK Istanbul, Turkey \\ * Corresponding Author : osman.gunay@ okan.edu.tr \\ ORCID:0000-0003-0760-554X
}

\section{ArticleInfo:}

DOI: $10.22399 /$ ijcesen.595645

Received : 24 July 2019

Accepted: 18 September 2019

\section{Keywords}

CT

Radiation Dose

TLD

$\mathrm{X}$ ray

\begin{abstract}
:
Today, many imaging tools have emerged in the medical field using ionizing radiation. Computed tomography (CT) is regarded the most creative and common modality among the other imaging devices. In CT imaging, radiation may scatter to the environment from the patient and the interaction medium. In this study, two CT scanners with different slice numbers were used to measure the scatter radiation dose to the environment. Alderson rando phantom was utilized in the acquired CT exams as human body simulation. Radiation dose levels at different distances were determined by placing thermoluminescence dosimeters in the surrounding environment (at different distances) during phantom's head-neck and thorax CT imaging. As a result, it has been found that the radiation dose varies between $13.90 \pm 1.96 \mu \mathrm{Sv}$ and $96.79 \pm 11.12 \mu \mathrm{Sv}$ in head and neck CT imaging. While, in thorax CT scan, the radiation dose varies between $5.28 \pm 0.84 \mu \mathrm{Sv}$ and $20.63 \pm 1.76 \mu \mathrm{Sv}$.
\end{abstract}

\section{Introduction}

Ionizing radiation causes somatic and genetic effects in the biological composition. The genetic effects of ionizing radiation mainly occur in the reproductive cells. Genetic mutations may arise and result in hereditary transient genotypic changes. Genetic effect is not observed in the irradiated individuals, but might propagate to the next generations. The irradiated cell must live and be fertilized for the emergence of the genetic effect [1,2]. Somatic effects basically occur in all other body cells except the reproductive cells. These effects are two parts, the definitive deterministic effect and the uncertain stochastic effect. Deterministic effects are the result of high-dose radiation exposure to large body areas. There is a threshold dose value in the deterministic effect formation and the effect increases proportionally with the dose. As a result of this effect; acute radiation syndrome, radiation burns, fibrosis, necrosis and sclerosis may emerge as late results. Stochastic effects are caused by prolonged exposure to low radiation doses and there is no specific threshold dose value. The biological effect increases with the dose, but the intensity is independent of the dose. Consequently, several sorts of diseases like leukemia, lung, and gastrointestinal and thyroid cancers might later develop. The science of radiology has early begun in 1985 after the discovery of x-rays. Medicine acquired a quantum leap with the discovery of $\mathrm{x}$-ray which was used primarily in radiography. With the technology development, x-ray was used in different imaging vehicles. One of the most advanced methods using 
X-ray source coupled with detectors and rotating around the object called computed tomography imaging (CT). Computed Tomography (CT) use has increased rapidly and become the most requested exam in the today's clinical practice since the introduction in 1970s. The use of IT in the last two decades has increased considerably in the UK and the United States (USA). In 2007, the number of investigations in the USA reached 72 million in 2007, a threefold increase compared to the 1990s. The rate of pediatric patients varies between $6 \%$ and $11 \%[3,4]$. The most important factor in the increase is the rapid technical development in CT and widespread use in clinical applications. The increase in CT use was especially in pediatric patients $[5,6]$. Multislice CT technology reduced the duration of shooting and facilitated the use of CT in children. Thus, the use of CT examinations increased rapidly without the need for anesthesia. Most of the increase in the use of CT in adults constitutes CTcolonography, lung screening, cardiac screening and whole-body screening programs in symptomatic patients. In computed tomography, more radiation doses are taken when compared to conventional $\mathrm{x}-$ ray examinations $[7,8]$. For example, in a lung $\mathrm{x}$-ray, the organ dose is approximately 0.01-0.15 mGy, while the thorax CT is 10-20 mGy. The amount of organ taken in CT depends on many factors [9]. Among the relevant factors are: patient's size, slice thickness, slices number, pitch, tube voltage and the current intensity. Most of these shooting parameters can be changed by radiologists or technicians during the examination [10]. In CT imaging, X-rays are directed towards the patient via various collimators. More recently, there has been a noticeable decrease in the level of radiation that the patient is exposed to in the new generation CT devices. However, X-rays are scattered around the patient or from some materials around the patient. In some cases, it may be necessary to have some people with patients during CT imaging. In particular, the children need to be held by accompanying person for keeping the patient's head fixed during CT scan in pediatric patients. Therefore, the persons close to the patients may be exposed to a certain amount of radiation dose. Those who remain close to the patient may be accidently pregnant women. Thus, it is very important to know the scatter radiation dose over the scanned object with CT. In the recent years, a number of studies have been performed using different methods related to the dose emitted to the environment in CT imaging and other imaging methods [11-17]. The main objective of this study was to determine the radiation dose scattered from the CT imaging devices. The dose to the close environment was estimated by several types of multi-slice CT equipment. In addition, radiation dose scattered throughout the head-neck and thorax imaging were also measured within this study.

\section{Materials and Methods}

This study was conducted in two different hospitals. One hospital had a Toshiba 320-slice CT and the other was equipped with Siemens 128-slice CT scanner. Head-neck and thorax CT scan was acquires over both phantoms. A well-known and widely used anthropomorphic Alderson RANDO phantom (ART) was utilized to emulate the human body. The Rando Phantom (female) is made from natural human skeleton molded into a tissue simulating plastic (density $=0.985 \mathrm{~g} \mathrm{~cm}-3$ ) to mimic human adult with 32 slabs. The female RANDO phantom corresponds to a complete body height of $155 \mathrm{~cm}$ and $50 \mathrm{~kg}$ mass. Thermoluminescence dosimeters (TLDs) were broadly used in absorbed dose measurements. TLDs calibration and postirradiation reading were performed in the Secondary Standard Dosimetry Laboratory (SSDL). SSDL has a Harshaw 4500 model reader that connects a computer with WinREMS software, which can read the TLD card and chip. The TLD reader heating process is carried out by hot nitrogen gas. The TLD chips are specially designed with doped lithium fluoride (LiF:Mg,Ti) crystals by Harshaw. The reader calibration factor (RCF) for the TLD and the element correction coefficients (ECCs) of the TLD chips were determined using the standard Cs-137 gamma source in the SSDL according to the manual of WinREMS software. In this study, 16 TLDs were used for each imaging system and four different CT scans were performed. 8 TLD were used for background radiation measurements. The total number of used TLDs was 72 pieces. The point of origin where the gantry entry meets the patient bed was accepted as a reference. The locations where TLD detectors were placed as follows: $10 \mathrm{~cm}, 20 \mathrm{~cm}$, $30 \mathrm{~cm}$ and $40 \mathrm{~cm}$ from the origin point. Four TLDs were placed at each of these distances. So, total of 16 TLDs were employed in each imaging (fig 1). Four different CT images were obtained including Head-neck and thorax regions on 128 slice CT and 320 slice CT scanners. The imaging protocols were likely set as determined by the hospital. After shooting, TLD detectors were read to determine scattered radiation dose at the center of Cekmece nuclear research.

\section{Results and Discussion}

8 TLDs were used in order to determine the background radiation level. The mean of the 8 TLD detectors was calculated and used as background 


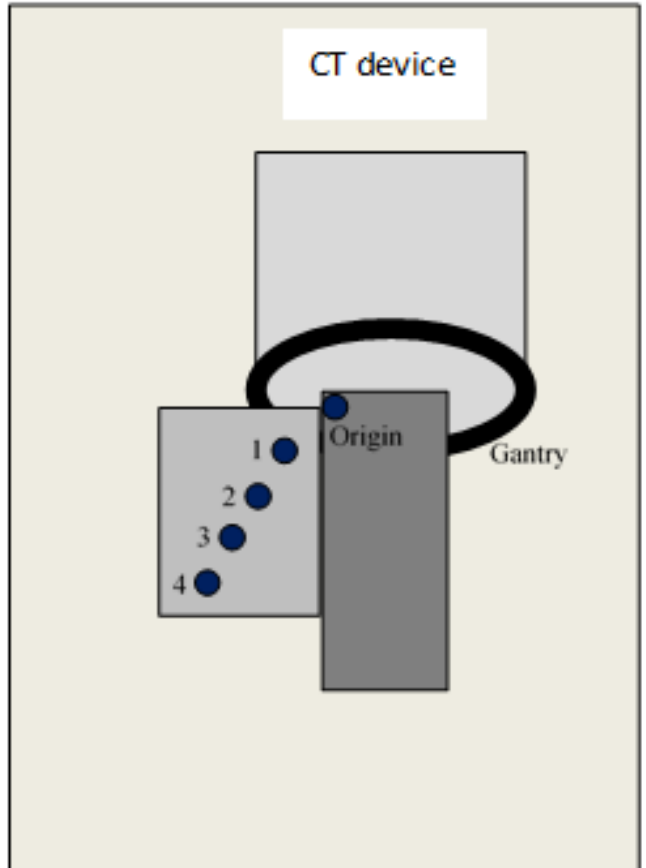

Figure 1.TLD locations in CT imaging $(1,2,3$ and 4 points are representing $10 \mathrm{~cm}, 20 \mathrm{~cm}, 30 \mathrm{~cm}$ and $40 \mathrm{~cm}$ from the origin point, respectively)

radiation level. The average of 4 TLDs at each measurement point was found and the background contribution was removed to pinpoint the level of scatter radiation dose. Table 1 shows CT imaging parameters. in head and neck imaging, mAs values were higher than thorax imaging. Table 2 shows the scatter radiation doses to the environment at different distances from the patient for head-neck imaging performed on 128 slice CT and 320 slice CT. The highest radiation level was found to be $96.79 \pm 11.12 \mu \mathrm{Sv}$ at a distance

Table 1. CT imaging parameters

\begin{tabular}{|l|l|l|l|l|}
\hline & \multicolumn{2}{|l|}{ Head-neck CT } & \multicolumn{2}{l|}{ Thorax CT } \\
\hline Slice no. & 320 & 128 & 320 & 128 \\
\hline $\mathrm{mAs}$ & 240 & 119 & 25 & 89 \\
\hline $\mathrm{kV}$ & 120 & 120 & 120 & 120 \\
\hline $\begin{array}{l}\text { CDTI } \\
\text { (mGy) }\end{array}$ & 36.2 & 9.55 & 1.8 & 3.44 \\
\hline $\begin{array}{l}\text { DLP } \\
\text { (mGy.cm) }\end{array}$ & 1095.9 & 358 & 57.4 & 129 \\
\hline
\end{tabular}

of $10 \mathrm{~cm}$ from the patient in 320 slice CT imaging. The lowest radiation level was found to be $13.90 \pm 1.96 \mu \mathrm{Sv}$ at distance $40 \mathrm{~cm}$ from the patient in 128 slice CT imaging. In both 128 slice CT and 320 slice $\mathrm{Ct}$, the level of radiation emitted into the environment decreased as the distance from the patient increased in the head- neck imaging.
Table 2. Radiation dose levels at different distances from the patient in head-neck imaging at 320 and 128 slice CT

\begin{tabular}{|l|l|l|l|}
\hline \multirow{3}{*}{$\begin{array}{l}\text { Number } \\
\text { of CT } \\
\text { slice }\end{array}$} & $\begin{array}{l}\text { CT } \\
\text { imaging } \\
\text { type }\end{array}$ & $\begin{array}{l}\text { Distance } \\
\text { from patients } \\
\text { head (cm) }\end{array}$ & $\begin{array}{l}\text { Radiation dose } \\
\text { and standard } \\
\text { deviation }(\mu \mathrm{Sv})\end{array}$ \\
\hline \multirow{3}{*}{320} & $\begin{array}{l}\text { Head- } \\
\text { Neck }\end{array}$ & 10 & $96.79 \pm 11.12$ \\
\cline { 2 - 4 } & $\begin{array}{l}\text { Head- } \\
\text { Neck }\end{array}$ & 20 & $83.46 \pm 7.54$ \\
\cline { 2 - 4 } & $\begin{array}{l}\text { Head- } \\
\text { Neck }\end{array}$ & 30 & $69.14 \pm 11.23$ \\
\cline { 2 - 4 } & $\begin{array}{l}\text { Head- } \\
\text { Neck }\end{array}$ & 40 & $37.70 \pm 12.01$ \\
\hline \multirow{3}{*}{128} & $\begin{array}{l}\text { Head- } \\
\text { Neck }\end{array}$ & 10 & $60.20 \pm 5.47$ \\
\cline { 2 - 4 } & $\begin{array}{l}\text { Head- } \\
\text { Neck }\end{array}$ & 20 & $49.73 \pm 3.84$ \\
\cline { 2 - 4 } & $\begin{array}{l}\text { Head- } \\
\text { Neck }\end{array}$ & 30 & $34.67 \pm 6.67$ \\
\cline { 2 - 4 } & $\begin{array}{l}\text { Head- } \\
\text { Neck }\end{array}$ & 40 & $13.90 \pm 1.96$ \\
\hline
\end{tabular}

For both 320 slice and 128 slice CT scanners, a stronger correlation was observed between the distance from the patient and the level of radiation emitted to the environment in the head-neck imaging $\left(\mathrm{R}^{2}=0.884\right.$ and $\mathrm{R}^{2}=0.891$, respectively) as illustrated in figure 2 and 3 . The scattered radiation level at the same distances at the 128 slice CT was found to be less than the 320 slice CT. Table 3 shows the levels of radiation scattered to the environment at different distances from the patient in the thorax imaging performed on 128

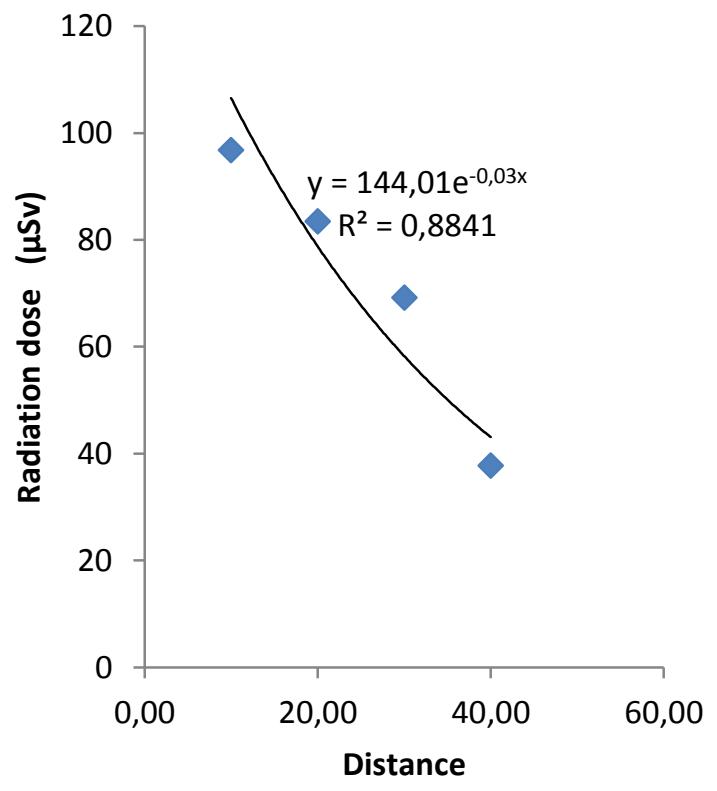

Figure 2. Radiation dose levels at different distances from the patient in head-neck imaging at 320 slice CT 


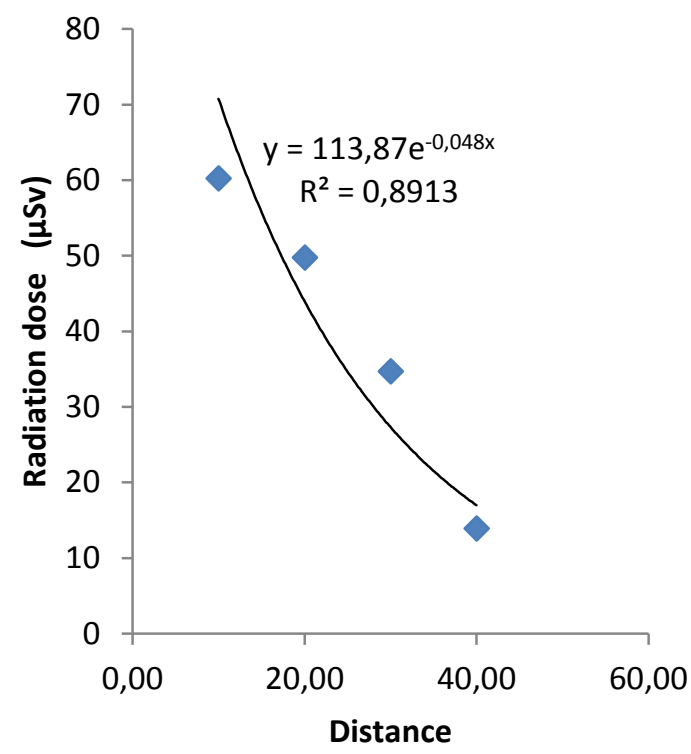

Figure 3. Radiation dose levels at different distances from the patient in head-neck imaging at 128 slice CT

slices CT and 320 slice CT. The highest radiation level was found to be $20.63 \pm 1.76 \mu \mathrm{Sv}$ at a distance of $10 \mathrm{~cm}$ from the patient in 128 slice CT imaging. The lowest radiation level was found to be $5.28 \pm 0.84$ $\mu \mathrm{Sv}$ at distance $40 \mathrm{~cm}$ from the patient in 320 slice CT imaging. In both 128 slice CT and 320 slice Ct, the level of radiation emitted into the environment decreased as the distance from the patient increased in the thorax imaging. In 320 slice CT, a stronger correlation was found between the distance from the patient and the level of radiation emitted to the environment in the thorax imaging $\left(\mathrm{R}^{2}=0.997\right)$ (fig $4)$.

Table 3. Radiation dose levels at different distances from the patient in thorax imaging at 320 and 128 slice CT

\begin{tabular}{|l|l|l|l|}
\hline \multirow{3}{*}{$\begin{array}{l}\text { Number } \\
\text { of CT } \\
\text { slice }\end{array}$} & $\begin{array}{l}\text { CT } \\
\text { imaging } \\
\text { type }\end{array}$ & $\begin{array}{l}\text { Distance } \\
\text { from } \\
\text { patients } \\
\text { head }(\mathrm{cm})\end{array}$ & $\begin{array}{l}\text { Radiation dose } \\
\text { and standard } \\
\text { deviation } \\
(\mu \mathrm{Sv})\end{array}$ \\
\hline \multirow{3}{*}{320} & Thorax & 10 & $14.51 \pm 3.27$ \\
\cline { 2 - 4 } & Thorax & 20 & $9.85 \pm 0.94$ \\
\cline { 2 - 4 } & Thorax & 30 & $7.24 \pm 0.95$ \\
\cline { 2 - 4 } & Thorax & 40 & $5.28 \pm 0.84$ \\
\hline \multirow{3}{*}{128} & Thorax & 10 & $20.63 \pm 1.76$ \\
\cline { 2 - 4 } & Thorax & 20 & $13.29 \pm 1.60$ \\
\cline { 2 - 4 } & Thorax & 30 & $9.52 \pm 0.65$ \\
\cline { 2 - 4 } & Thorax & 40 & $6.60 \pm 1.08$ \\
\hline
\end{tabular}

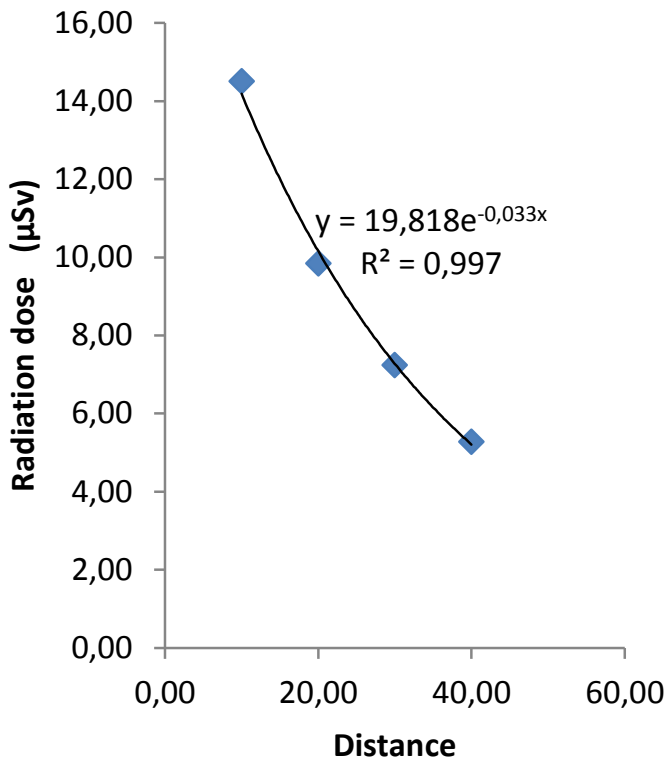

Figure 4. Radiation dose levels at different distances from the patient in thorax imaging at 320 slice CT

Also, the correlation between the distance from the patient and the level of radiation emitted to the environment in the thorax imaging was found massive with $\mathrm{R}^{2}=0.996$ (fig 5). The scattered radiation level at the same distances for 320 slice CT was found to be less than the 128 slice CT.In 2016, Tekin et al. determined the radiation dose rate scattered to the environment in CT imaging.

The radioactive dose rate measurements in the study were performed using Polimaster Survey Meter (PM1405). In the abdominal CT imaging, the radiation dose rate at a distance of $20 \mathrm{~cm}$ from the gantry was $98.1 \mathrm{mSv} / \mathrm{h}[18]$.

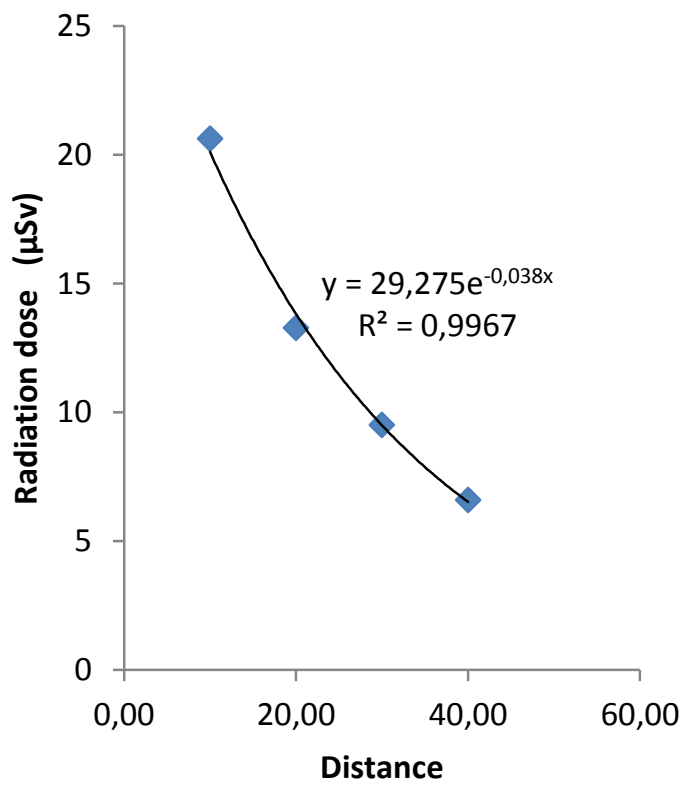

Figure 5. Radiation dose levels at different distances from the patient in thorax imaging at 320 slice CT 
In another study in 2018, the radiation dose rate at a distance of $20 \mathrm{~cm}$ from the gantry was found to be $48.5 \mathrm{mSv} / \mathrm{h}$ [19]. In both studies, the radiation dose rate at different distances from the gantry was measured. It was determined that the radiation dose rate decreased as the distance from the gantry increased. Our study was performed with TLD dosimeters and it was found that the radiation dose level decreased as the distance increased. Finally, it was found that the level of radiated radiation in the head-neck imaging was higher than the thorax imaging. This may be due to the greater amount of bone in the head than in the thorax, and the use of more radiation in the imaging of the head and neck. Thus, the scattered radiation may be more

\section{Conclusion}

It was deduced that the scatter radiation dose to the environment ranged from $5.28 \pm 0.84 \mu \mathrm{Sv}$ to $96.79 \pm 11.12 \mu \mathrm{Sv}$ across distance interval of $10-40$ $\mathrm{cm}$ from the patient in head /or thorax CT scan. It seems that the level of scatter radiation in the headneck imaging was higher than the thorax imaging and the person assisting the patient should stay as far as possible from the patient.

\section{Acknowledgement}

The authors would like to thank those who helped in this study.

\section{References}

[1] Beir, V. I. I. "Health risks from exposure to low levels of ionizing radiation." The National Academies report in brief, 2005.

[2] Mitelman F, Johansson B, Mertens FE. Mitelman database of chromosome aberrations in cancer. Cancer Genome Anatomy Project, 2007.

[3] Hall EJ, Brenner DJ. Cancer risks from diagnostic radiology. Br J Radiol.2008 May;81(965):362-78.

[4] Berrington de Gonzalez A, Mahesh M, Kim KP, Bhargavan M, Lewis R, Mettler F, Land C. Projected cancer risks from computed tomographic scans performed in the United States in 2007. Arch Intern Med. 2009 Dec 14; 169(22):2071-7.

[5] Strauss, K. J., Goske, M. J., Towbin, A. J., Sengupta, D., Callahan, M. J., Darge, K., ... \& Prince, J. S. Pediatric chest CT diagnostic reference ranges: development and application. Radiology, 2017; 284(1), 219-227.

[6] Mettler FA Jr, Wiest PW, Locken JA, Kelsey CA. CT scanning: patterns of use and dose. J Radiol Prot 2000;20:353-9.

[7] White KS. Helical/spiral CT scanning: a pediatric radiology perspective. Pediatr Radiol 1996;26:5-14.
[8] Linton OW, Mettler FA Jr. National conference on dose reduction in CT, with an emphasis on pediatric patients. AJR Am J Roentgenol 2003;181:321-9.

[9] Brenner DJ, Elliston CD. Estimated radiation risks potentially associated with full-body CT screening. Radiology 2004; 232:735-8.

[10] McNitt-Gray MF. AAPM/RSNA physics tutorial for residents topics in $\mathrm{CT}$ : radiation dose in $\mathrm{CT}$. Radiographics 2002; 22:1541-53.

[11] Günay, O., Abamor, E. Environmental radiation dose rate arising from patients of PET/CT. International Journal of Environmental Science and Technology, 1-8. (2018).

[12] V.Every, R.J. Petty. Measurements of computed tomography radiation scatter. Australas Phys.Eng. Sci. Med.1992; 15(1) pp.15-24.

[13] Palac1, H., Günay, O., Yarar, O. Türkiye'deki Radyasyon Güvenliği ve Koruma Eğitiminin Değerlendirilmesi. Avrupa Bilim ve Teknoloji Dergisi, (14), 2014; 249-254.

[14] Stoeckelhuber BM, Leibecke T, Schulz E, et al. Radiation dose to the radiologist's hand during continuous CT fluoroscopy-guided interventions. Cardiovasc Intervent Radiol. 2005; 28: pp. 589-594.

[15] Kuru, L. İ., Gunay, O., Palac1, H., \& Yarar, O. Bilgisayarlı tomografilerde hastanın aldığı efektif radyasyon dozunun belirlenmesi. Balıkesir Üniversitesi Fen Bilimleri Enstitüsü Dergisi, 21(1), (2019), 436-443.

[16] M.Salvado et.al., Monte Carlo calculation of radiation dose in CT examinations using phantom and patient tomographic models. Radiation Protection Dosimetry, 2005; 114(1-3):364-8.

[17] D.Richard et.al.,.Patient and Personnel Exposure during CT Fluoroscopy-guided Interventional Procedures. RSNA Radiology V. 2000; 216 (1).

[18] Tekin H.O., Manici T. and Ekmekci C. "Investigation of backscattered dose in a computerized tomography (CT) facility during abdominal CT scan by considering clinical measurements and application of Monte Carlo method." Journal of Health Science 4, 2016; 131-134.

[19] Tekin H. O., Cavlı, B., Altunsoy, E. E., Manici, T., Ozturk, C., and Karakas, H. Ml. "An investigation on radiation protection and shielding properties of 16 slice computed tomography (CT) facilities." International Journal of Computational and Experimental Science and Engineering, 2018; 4.2: 37-40. 